\title{
Counting and Bare Plurals
}

\author{
Tom Werner \\ Rutgers University
}

\section{Introduction}

Contrasts of the following sort have been noticed by such authors as Dowty (1979) and Smith (1997).

(1) John ate some sandwiches (in an hour).

(2) John ate sandwiches (for an hour).

The first sentence - with a quantified NP as direct object - has a telic reading, as the adverbial clause in parentheses shows. What is described is an action that can be completed in a finite amount of time. The second sentence - with a bare plural object - has an atelic reading. There is no suggestion of a finite task, but rather of a continuous activity to be carried on indefinitely. The contrast between these sentences might lead one to the natural assumption that the atelicity in (2) is contributed by the bare plural itself. Smith (1997: 55), for example, appears to reach such a conclusion. A related contrast can be seen in sentences about counting.

(3) John counted some sheep (in an hour).

(4) John counted sheep (for an hour).

The associated adverbials show that the telicity/atelicity contrast carries over to this pair of sentences. However, there is a crucial difference between this pair and the first. Whereas (2) is plausibly about a repetition of the activity mentioned in (1), sandwicheating, the counting mentioned in (4) does not involve a mere repetition of the counting involved in (3). If it did, the counting in (4) would involve a repeated assignment of cardinalities to sets of sheep, rather than the continuous assignment of numbers to individual sheep without any obvious regard for their membership in some given set.

Another crucial difference between (3) and (4) concerns the criteria for a correct count. For the counting in (3) to be correct, no individual sheep may be assigned a number more than once. But (4) involves no such restriction. In this counting, individual sheep may be counted more than once. If John counts the sheep that are kept in a particular pen, he is obligated to count each sheep only once. If John counts sheep crossing over a stile, he may count a sheep each time it crosses the stile, even if it crosses more than once.

In this paper, I attempt to make sense of the difference in contrast between (1) and (2) on the one hand, and (3) and (4) on the other. I show that the telic/atelic distinction is not the only one at work, but in fact a third sense makes its way into these sentences - an iterative telic reading. These readings are of special interest here 
because they emerge in sentences with bare plural objects. This fact suggests that in atelic sentences, atelicity is not simply the contribution of the bare plural, and that the semantics of the bare plural must make it compatible with both atelic and iterative telic sentences.

I propose that bare plurals denote functions from temporal intervals to sets. For ongoing activities such as atelic counting, the set contributed by the bare plural is fixed by the duration of the activity. For iterative cases, the bare plural provides a sequence of sets, one for each interval of the iterated event. Any two of these sets may be identical, but they needn't be.

Bare plurals will contrast with quantified NPs, such as some sheep in (3). I propose that in the relevant contexts, these NPs also denote functions from intervals to sets. However, I propose that the output of these functions is contextually fixed. (This will be indicated by a superscript in their semantic translation.) As a result, the functions will be constant, and this will explain why such NPs behave differently than bare plurals.

First, these quantified NPs are odd in sentences such as atelic counting sentences. Atelic counting is a continuous activity. If the set counted is given in advance, there won't be a mesh between the duration of the count and the set. Second, in iterative contexts, the function denoted by the quantified NP will yield the same set for each interval.

This second difference shows up in the following contrast.

(6) Some dogs keep barking.

(5) is true just in case at repeated intervals, some dog or other barks. The truth of (6) under the relevant reading requires an additional condition -- that the dogs that bark all come from the same set of dogs.

The semantic distinction between bare plurals and other relevant NPs provides an explanation for a further distinction. (7) below can only mean that John repeatedly counted the same set of sheep. (8) can be true in a case where each time John counted a set of sheep, it was a different set.

John repeatedly counted some sheep.

John repeatedly counted sheep.

This difference is explained if some sheep denotes a constant function and sheep does not. For each repetition in (7), the function will yield the same set. For any repetition in (8), the function can yield a different set.

The paper is organized as follows. In Section 2, I begin with an analysis of telic counting and a counting of individuals. This analysis incorporates the claim that to count is to perform some operation on a set. I argue that telic counting is subject to certain rules that are not part of the semantics. In Section 3, I argue that bare plurals are temporally dependent NPs. In Section 4, I put the two claims together and argue that bare plurals denote functions from temporal intervals to sets. In Section 5, 
I extend the analysis of counting to atelic cases. I also argue for an iterated accomplishment reading of counting sentences with bare plurals. I show how the semantics of bare plurals allows them to appear in both atelic and iterated accomplishment sentences. Finally, I suggest that atelic counting is regulated by its own extra-linguistic rules, according to the purposes of the count.

\section{Telic Counting}

\subsection{Counting sets}

The following sentence makes reference to a paradigmatic case of counting.

(9) John counted some sheep.

Intuitively, (9) is true just in case during some past interval John associates successive cardinal numbers to individual members of some set of sheep, starting with 1 and assigning the highest number as the cardinality of the entire set.

Various tests show that count as it appears in (9) is an accomplishment predicate, under the categorization of Vendler (1967). (See also Dowty (1979).)

First, accomplishment predicates are compatible with telic rather than atelic adverbials. As already observed, this is true of count some sheep as shown here.

(10) John counted some sheep in an hour / ??for an hour.

In addition, a sentence with an accomplishment verb in the past progressive does not entail the corresponding sentence in the simple past. This lack of entailment is seen with count in the context of (9). Thus, (11) does not entail (12).

(11) John was counting some sheep. $\quad \neq>$

(12) John counted some (those) sheep.

Accomplishment predicates are also characterized by their interaction with finish vs. stop. (See Smith (1997).) Embedded under finish, accomplishment predicates entail completion. This is not the case when they are embedded under stop.

John finished counting some sheep. $\quad(=>(12))$

John stopped counting some sheep. $\quad(\Leftrightarrow \neg(12))$

If John finished counting some sheep, he completed the task and assigned a cardinality to the entire set. Then (12) is true. If John stopped counting some sheep, he did not complete the task and did not assign a cardinality to the entire set. (12) is not true in this case.

Finally, an accomplishment sentence with almost is ambiguous. This ambiguity is found in telic counting sentences. 
By one sense of (15), John nearly commenced a counting of some set of sheep. By another sense of (15), John nearly completed a counting of some set of sheep.

Dowty (1979) analyses accomplishments as having an activity part and an achievement part. The activity part of accomplishment counting would be the part where successive cardinal numbers are assigned to members of a given set. The achievement part would be where the highest such number is assigned as the cardinality of the set.

I am now ready to give a semantic value for telic count. The formulation I give here is tentative and will be subject to further revision.

To capture the idea of counting, I assume a pointer that moves along a tape of numbered squares, starting at 0 . The pointer is advanced just once for every member of the set, and the number at the final location of the pointer is taken as the cardinality of the set.

The semantic value of count is then as in (16).

$$
\begin{aligned}
& \lambda \mathrm{P}_{\mathrm{et}} \lambda \mathrm{x}_{\mathrm{e}}[[\forall \mathrm{y}(\mathrm{y} \in \mathrm{P} \leftrightarrow \text { move-pointer' }(\mathrm{x}, \mathrm{y}))] \& \\
& \text { [ assign' }(\mathrm{x}, \mathrm{FL},|\mathrm{P}|)] \text { ] }
\end{aligned}
$$

move-pointer $(x, y)$ is true just in case the counting individual, $x$, advances the pointer one space along the tape for the counted individual, $y$. assign' $(x, F L,|P|)$ is true just in case the counting individual, $x$, assigns the number at the final location of the pointer, $F L$, as the cardinality of the set, $P$.

The first conjunct in (16) represents the activity part of the accomplishment and the second conjunct in (16) represents the achievement part.

The following then gives a translation for (9) (ignoring tense ${ }^{1}$ ).

$$
[\forall \mathrm{y}(\mathrm{y} \in \text { some-sheep } \leftrightarrow \text { move-pointer' }(\mathrm{j}, \mathrm{y}))] \&
$$

$$
\text { [ assign' (j, FL, |some-sheep } \mid \text { ] }
$$

(17) is true just in case John advances the pointer once for every member of some set of sheep, and then assigns the number at the final location of the pointer as the cardinality of the set.

\subsection{Counting individuals}

The direct object of the verb count can be an expression of type e, as the following examples show.

(18) John counted Mary.

(19) John counted Mary and Sue. 
The intuitive meaning of these sentences is that John included Mary, or Mary and Sue, in the count of some set. What is being counted here are individuals, or plural individuals, and I will call this kind of counting individual counting.

The semantic value for count when it is used for individual counting is given in (20).

$$
\lambda \mathrm{y}_{\mathrm{e}} \lambda \mathrm{x}_{\mathrm{e}} \exists \mathrm{X}_{\mathrm{et}}[\text { include-in-count' }(\mathrm{x}, \mathrm{y}, \mathrm{X})]
$$

include-in-count $(x, y, X)$ is true just in case the counting individual, $x$, includes the individual $y$ in a counting of the set $X$.

The direct object of count with an individual counting reading can also be a bare plural.

(21) John counted sheep.

This sentence has an atelic reading, but I set that aside until later. I assume that in individual counting readings, the bare plural simply denotes a kind. Kinds in the semantics literature are generally agreed to be individuals. Given this assumption, sheep in (21) would be an expression of type e, and nothing special needs to be said about it.

The direct object of count can also be an expression denoting a generalized quantifier.

(22) John counted every person.

(23) John counted most people.

(24) John counted a few people.

(25) John counted few people.

These sentences have the intuitive meaning of including every, most, a few people etc. in a count. They will be treated the same as any sentence where a generalized quantifier appears in an argument position otherwise occupied by an expression of type e.

\subsection{Miscounting}

The semantics for telic count given in (16) doesn't allow for miscounts. This is not a desirable result, judging by such sentences as (26).

John counted some sheep, but he got it wrong.

Although John didn't count the sheep properly, we still say that he counted them.

There are two obvious ways that John could fail to assign the right cardinality to the set of sheep he is counting. He could assign more than one cardinal number to any member of the set, or he could fail to assign a cardinal number at all to some member of the set. ${ }^{2}$ The semantics in (16) must be revised to include these cases. 
I will assume that John assigns cardinal numbers to individuals not directly as members of the set, but as members of subsets of the set. If an individual is included in more than one subset, it will be counted twice. If an individual is not included in any subset, it won't be counted at all.

I propose then that the semantics of telic count makes mention of sets of indices that map to subsets of a given set. In the revised semantics for telic count in (27), $X_{P}$ is a variable over such sets of indices. $P_{i}$ is a subset of $P$ with the index $i$.

$$
\begin{aligned}
\lambda \mathrm{P}_{\mathrm{et}} \lambda \mathrm{x}_{\mathrm{e}}\left[\left[\exists \mathrm{X}_{\mathrm{P}}: \forall \mathrm{i}\left(\mathrm{i} \in \mathrm{X} \rightarrow \forall \mathrm{y}\left(\mathrm{y} \in \mathrm{P}_{\mathrm{i}} \leftrightarrow \operatorname{move-pointer}(\mathrm{x}, \mathrm{y})\right)\right)\right] \&\right. \\
{\left.\left[\operatorname{assign}^{\prime}(\mathrm{x}, \mathrm{FL},|\mathrm{P}|)\right]\right] }
\end{aligned}
$$

Telic count is an expression of type $<<e, t>,<e, t>>$. It takes an expression of type $<\mathrm{e}, \mathrm{t}>--$ an expression denoting a set -- and gives back a function from entities to truth-values. (This formula will be revised once more in a future section.)

(28) gives the semantic translation for (9), given (27).

$$
\begin{aligned}
& \left.\left[\exists \mathrm{X}_{\text {some-sheep }}: \forall \mathrm{i}\left(\mathrm{i} \in \mathrm{X} \rightarrow \forall \mathrm{y}\left(\mathrm{y} \in \text { some-sheep }_{\mathrm{i}} \leftrightarrow \text { move-pointer' }^{\prime} \mathrm{j}, \mathrm{y}\right)\right)\right)\right] \& \\
& \text { [ assign' (j, FL, |some-sheep } \mid) \text { ]] }
\end{aligned}
$$

(28) is true just in case John assigns a cardinal number just once to every member of every subset of some set of sheep and assigns the final cardinal number as the cardinality of the whole set, where the subsets are determined by some set of indices.

We can now distinguish correct from incorrect telic counting. Telic counting is correct when the set of indices selected maps onto a partition of the set being counted, where a partition on a set $S$ is a set of non-empty, non-overlapping subsets of S such that the union of these subsets is identical to S. By (28), if the set of indices maps to a partition of the set of sheep, John will assign cardinal numbers to all members of the set of sheep, but only once. The final cardinal number he assigns will in fact represent the cardinality of the entire set. ${ }^{3}$

Correct counting then comes about from a regimentation of counting. The regimentation is via the choice of the set of indices, that is, the set of subsets of the set being counted. Sentences such as (26) tell us, however, that this regimentation should not be part of the semantics of telic count. Rather, the semantics of telic count should be such that the activity it describes can be regimented in the appropriate way.

\subsection{Hypothesis about bare plurals in counting sentences}

Of the two senses of count so far discussed, I take the telic counting sense to be primary and the individual counting sense to be derivative. Individual counting sentences always require a prior counting of some set.

It follows that counting is primarily something done of sets. Then I provisionally assume that in atelic counting sentences such as the following, the bare plural denotes a set. 
Just what set sheep denotes in (29) will be investigated throughout the remainder of the paper. We can already see that since John can count sheep for any length of time, the set denoted by sheep has to be in some way determined by the duration of the counting.

In the following section, I will show independent evidence that bare plurals are temporally dependent expressions.

\section{The Temporal Dependency of Bare Plurals}

Musan (1995) discusses the temporal dependence and independence of various NPs. Her discussion includes the case of bare plurals in generic sentences. In this section I will look at bare plurals in non-generic contexts. ${ }^{4}$

Musan assumes that NPs are either temporally independent or dependent on the sentence predicate. This assumption seems to cover bare plurals in sentences such as the following.

(30) I used to feed butterflies.

(31) I used to feed some butterflies when they were caterpillars.

(32) \#I used to feed butterflies when they were caterpillars.

(32) is odd because the time of the feeding is specified to be when the individuals in question were caterpillars. At this time, they obviously cannot also have been butterflies. If bare plurals are temporally dependent on the predicate, the sentence should be ruled out, as it is.

However, a more complicated story begins to emerge as other examples are considered.

(33) \#Caterpillars are butterflies.

(34) Caterpillars turned into butterflies.

In (33), the individuals that are caterpillars cannot at the same time be butterflies. Under the assumption that the bare plural is temporally dependent on the predicate, the sentence is (correctly) predicted to be odd.

The case for (34), though, is more complicated. It is not immediately clear how the bare plural could be temporally dependent on the predicate, since the time of an individual turning into a butterfly is precisely a time when it is not a caterpillar.

Such problematic cases are not uncommon. Consider the following.

(35) John cured sick rabbits.

(36) \#John cured healthy rabbits. ${ }^{5}$ 
The time of John's curing the rabbits is a time when the rabbits are not fully sick or healthy. But only the bare plural sick rabbits and not the bare plural healthy rabbits is acceptable in the post-verbal position in (35) and (36).

These facts suggest that to give a complete story of the temporal dependency of bare plurals, a link will need to be developed between the Aktionsarten of predicates and the $\theta$-roles they assign. I do not give a complete account here but the basic idea is as follows.

Kamp and Reyle (1993) discuss a temporal schema with three stages in terms of which Vendler's (1967) classification of verbs can be analyzed. The three stages of the schema are (I), the preparatory stage, (II), the culmination stage, and (III), the result stage. Activity verbs describe episodes associated with Stage I; achievements, episodes associated with Stage II; and accomplishments, episodes associated with Stages I and II.

Assume that cure is an achievement verb. cure then describes an episode associated with the culmination stage of the schema. The time of the predicate will therefore be linked to this culmination stage. But the individuals that John cures in (35) are not sick rabbits at the culmination stage. They are sick rabbits at the preparatory stage. The preparatory stage must somehow be represented in the sentence. I propose that it is represented through the $\theta$-role assigned by cure to its direct object in (35). If the predicate applies at time $t$, the $\theta$-role will be associated with a temporal interval that is a function of $t, f(t)$. It is to this time that the bare plural will be dependent.

I therefore consider bare plurals to be dependent not directly on the time of the predicate, but on a derivative time. If the interval that the predicate applies is $t$, the bare plural will be dependent on an interval $f(t)$. The particular function $f$ will depend both on the Aktionsarten of the predicate and on the $\theta$-roles assigned by that predicate.

I propose to represent each such function as a subscript on the argument of the predicate, which gives the following as translations of (35) and (36).

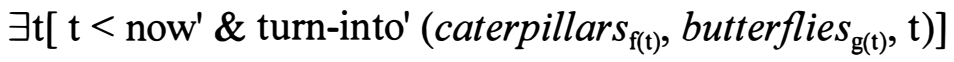

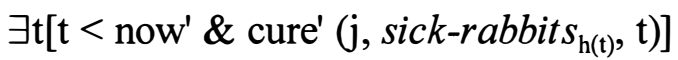

In $\left(35^{\prime}\right)$, for any interval of turning-into $t$, the individuals undergoing the change will have been caterpillars at the interval $f(t)$ and will be butterflies at the interval $g(t)$. $t$ will be associated with Stage II, $f(t)$ with Stage I, and $g(t)$ with Stage III of the episode of turning into.

In (36'), for any interval of curing denoted by $t$, the individuals undergoing the cure will have been sick rabbits at the interval $h(t)$. $t$ will be associated with Stage II and $h(t)$ with Stage I of the episode of curing.

Although I have only discussed achievement verbs here, I assume that the point is general and that bare plurals in argument positions of state, activity, and accomplishment verbs will be temporally dependent on times associated with the $\theta$ roles assigned by the predicate. 


\section{Bare Plurals in Iterative Contexts}

I have made two assumptions about bare plurals. The first is that, at least in the context of counting sentences, they denote sets. The second is that they are temporally dependent. From this point on, however, I want to work with the combined assumption that bare plurals denote functions from temporal intervals to sets. This makes bare plurals expressions of type $<\mathrm{i},<\mathrm{e}, \mathrm{t}>>$, where $i$ is the type of a temporal interval.

As for NPs such as some sheep, we have seen that they are interchangeable with bare plurals, which suggests that their semantic type should also be $<\mathrm{i},\langle\mathrm{e}, \mathrm{t}\rangle\rangle$, and that they appear to be temporally independent. I therefore let these NPs denote constant functions to some contextually given set (unless in the context they denote generalized quantifiers). Since the set is contextually given, it is temporally independent of the predicate (that is, of the temporal interpretation of the $\theta$-role).

I indicate that these functions are constant by a superscript in the semantic translation. Then sheep and some sheep differ as follows.

$$
\begin{aligned}
& \text { sheep' }^{\prime}=\lambda \mathrm{i}\left[\text { sheep }_{\mathrm{i}}\right] \\
& \text { some-sheep }^{\prime}=\lambda \mathrm{i}\left[\text { sheep }_{\mathrm{i}}^{\mathrm{k}}\right]
\end{aligned}
$$

The superscript says that the function at any index yields the same set.

These assumptions can be tested by seeing how the respective NPs behave in iterative contexts. Iterative contexts involve series of temporal intervals. Bare plurals, if they truly denote functions from intervals to sets, should yield series of possibly different sets associated with these intervals. NPs which denote constant functions should yield repeated instances of the same set.

The following sentences provide the right context for this test.

Some dogs keep barking.

Dogs keep barking.

(39) is ambiguous, but the reading of interest here makes the sentence true in a situation where there is some identifiable set of dogs, members of which bark from time to time. (40) has only one reading. Dogs bark from time to time, but they are not necessarily members of a single identifiable set of dogs.

$\left(39^{\prime}\right)$ and $\left(40^{\prime}\right)$ are translations for (39) and (40).

Iteration is represented by quantification over sets of intervals. Both translations say that at each interval, members of an associated set of dogs bark. But in one case that set is always the same, whereas in the other it may vary.

$$
\begin{aligned}
& \exists X: \forall \mathrm{t}\left[\mathrm{t} \in \mathrm{X} \rightarrow \operatorname{bark}^{\prime}\left(f\left(\operatorname{dogs}_{\mathrm{f}(\mathrm{t})}^{\mathrm{k}}\right), \mathrm{t}\right)\right] \\
& \exists \mathrm{X}: \forall \mathrm{t}\left[\mathrm{t} \in \mathrm{X} \rightarrow \operatorname{bark}^{\prime}\left(f\left(\operatorname{dog}_{\mathrm{f}(\mathrm{t})}\right), \mathrm{t}\right)\right]
\end{aligned}
$$

$X$ is a variable over sets of intervals. $f$ represents a choice function which takes a set as input and gives an individual (possibly a plural individual) as output. The difference 
between $\left(39^{\prime}\right)$ and $\left(40^{\prime}\right)$ is in the function denoted by the NP. For (40'), every interval $t$ is associated with a possibly different set. For (39'), because of the superscript, every interval $t$, is associated with the same set.

The interpretations of (39') and (40') then accord with intuitions about (39) and (40), where only (39) requires all the dogs to be from one set.

I now revise the semantics for telic count to include a variable over intervals. (41) is the semantic value for telic count. (43) is the translation of (42) (ignoring tense).

$$
\begin{aligned}
\lambda \mathrm{P}_{\mathrm{i}(\mathrm{et})} \lambda \mathrm{x}_{\mathrm{e}} \lambda \mathrm{t}_{\mathrm{i}}\left[\left[\exists \mathrm{X}_{\mathrm{Pf}(\mathrm{t})}: \forall \mathrm{j}\left(\mathrm { j } \in \mathrm { X } \rightarrow \forall \mathrm { y } \left(\mathrm { y } \in \left(\mathrm{P}_{\mathrm{f}(\mathrm{t}))_{\mathrm{j}}}\right.\right.\right.\right.\right. & \\
& \left.\leftrightarrow \text { move-pointer' }(\mathrm{x}, \mathrm{y}, \mathrm{t})))] \&\left[\operatorname{assign}^{\prime}\left(\mathrm{x}, \mathrm{FL},\left|\mathrm{P}_{\mathrm{f}(\mathrm{t})}\right|, \mathrm{t}\right)\right]\right]
\end{aligned}
$$

(42) John counted some sheep.

$$
\begin{aligned}
& {\left[\exists \mathrm{X}_{\text {sheep } \mathrm{k} / \mathrm{f}(\mathrm{t})}: \forall \mathrm{i}\left(\mathrm { i } \in \mathrm { X } \rightarrow \forall \mathrm { y } \left(\mathrm{y} \in\left(\text { sheep }_{\mathrm{f}(\mathrm{t})}^{\mathrm{k}}\right)_{\mathrm{i}}\right.\right.\right.}
\end{aligned}
$$

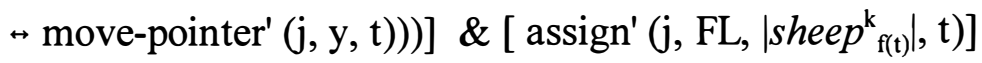

\section{Return to Counting Sentences}

\subsection{Atelic counting}

The same tests that showed telic count to be an accomplishment verb show atelic count to be an activity verb.

Sentences containing the predicate count sheep are compatible with atelic rather than telic adverbials, under their most natural interpretation.

$$
\text { John counted sheep for an hour / \#in an hour. }
$$

This result suggests that (44) makes reference to no particular task to be completed in a fixed amount of time.

An atelic count sentence in the past progressive should entail the corresponding past tense sentence, and indeed (45) entails (46).

(45) John was counting sheep. $\quad=>$

(46) John counted sheep.

Activities are stopped rather than finished, and in fact count sheep is more naturally embedded under stop than under finish.

(47) ?John finished counting sheep.

(48) John stopped counting sheep. 
finish has one meaning that is synonymous with stop. The question mark on (47) is meant to indicate that finish can only have that meaning in this sentence, and not a meaning by which the sentence would be true just in case John completed some count.

Finally, remembering that sentences with activity verbs and almost are not ambiguous, we note that a sentence with count sheep and almost is not ambiguous either, when interpreted in the most obvious way.

John almost counted sheep.

This sentence can only mean that John nearly commenced counting sheep. If he so much as started the activity, (49) would be false.

These tests establish that atelic count is an activity verb. I propose then that the only difference between telic and atelic count is that the latter lacks an achievement stage.

The semantic value of atelic count is as in (50). (51') is the translation for (51).

$$
\begin{gathered}
\lambda \mathrm{P}_{\mathrm{i}(\mathrm{et})} \lambda \mathrm{x}_{\mathrm{e}} \lambda \mathrm{t}_{\mathrm{i}}\left[\exists \mathrm{X}_{\mathrm{pf}(\mathrm{t})} ; \forall \mathrm{j}\left(\mathrm { j } \in \mathrm { X } \rightarrow \forall \mathrm { y } \left(\mathrm{y} \in\left(\mathrm{P}_{\mathrm{f}(\mathrm{t})}\right)_{\mathrm{j}}\right.\right.\right. \\
\leftrightarrow \text { move-pointer' }(\mathrm{x}, \mathrm{y}, \mathrm{t})))]
\end{gathered}
$$

$$
\begin{aligned}
& \text { John counted sheep. (atelic) }
\end{aligned}
$$

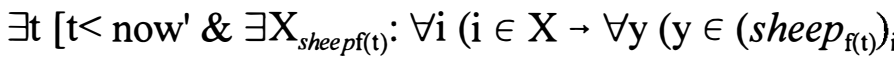

$$
\begin{aligned}
& \leftrightarrow \text { move-pointer' }(\mathrm{j}, \mathrm{y}, \mathrm{t})))]
\end{aligned}
$$

By (50), atelic counting involves assigning cardinal numbers to members of subsets of some set. But the set is only given by the activity itself. It is the set of individuals encountered over the duration of the count. The longer the count, the greater the extent of the set (barring repetitions).

Now it is clear why bare plurals are natural in atelic count sentences, while other NPs are less so. Bare plurals denote functions from intervals to sets, I have claimed. Given a particular interval, such a function can yield a set of individuals encountered over that interval.

The other NPs under consideration here are less suited to such contexts, since they denote functions whose value is contextually fixed, i. e. a predetermined set. Since the set is predetermined, there will in general be no fit between the activity and the set, as there is with a bare plural.

Consider the following example.

\section{?John counted some sheep for an hour.}

In (52), the adverbial forces an atelic count reading. This sentence could still be appropriate in a scenario where John counted a given set of sheep for an hour without finishing the count. But (52) would not be appropriate in typical scenarios for atelic 
counting such as counting sheep crossing a stile, where the set counted is not given in advance but only emerges with the count.

A question about atelic counting remains, however, given the semantic value I have given in (50) for telic count. Do any rules at all constrain this activity? I claim that there are such rules, depending on the purpose of the count, but these should not be part of the semantics. I return to this issue in Section 5.5 below.

\subsection{A paradigm}

Counting sentences, I have argued, can make reference to three kinds of counting, telic, individual, and atelic. But count is not the only verb that appears in sentences of these types. Another such verb is stack.

(53) John stacked some pancakes.

telic

(54) John stacked this pancake. individual

(55) John stacked pancakes. atelic

(53) is about a task that can be completed in a finite length of time. (54) means that a particular pancake was included in some stacking. (55) is about an activity that can be carried on indefinitely.

This pattern shows that we are dealing with a paradigm. It turns out that there are at least two additional members of this paradigm.

\subsection{Iterated activities and iterated accomplishments}

The following sentences each have an iterative activity and iterated accomplishment reading.

(56) John repeatedly counted sheep.

(57) John repeatedly stacked pancakes.

(58) John counted sheep three times.

(59) John stacked pancakes three times.

Consider (56).

(56) would be true under its iterated activity reading in a scenario where, for example, John over and over took up a count of sheep crossing a stile, each time starting the count at 1.

(56) would be true under its iterated accomplishment reading in a scenario where, for example, John over and over counted different sets of sheep, each time assigning a cardinality to whichever set he was counting just then.

The iterated accomplishment reading is of special interest since it occurs with bare plurals. Various tests support the claim that there is such a reading.

Telic adverbials are admissible in such sentences. 
(60) John repeatedly counted sheep in an hour.

(61) John counted sheep in an hour three times.

(60) has a reading where each counting of a set of sheep was completed in an hour. (61) has a reading where each of three countings was completed in an hour.

The stop/finish contrast indicates that there is an iterated accomplishment reading.

(62) John repeatedly stopped counting sheep.

(63) John repeatedly finished counting sheep.

(62) has a reading where John repeatedly gave up on assigning cardinalities to sets of sheep and (63) a reading where he repeatedly assigned cardinalities to sets of sheep.

The almost test supports the claim that these sentences truly have an iterated accomplishment reading.

(64) John repeatedly almost counted sheep.

(65) John almost counted sheep three times.

Under an accomplishment reading, both these sentences are ambiguous. (64) means that either John nearly commenced a telic count of different sets of sheep on different occasions, or that he nearly completed a telic count of different sets of sheep on different occasions. (65) has a related pair of readings.

Given the reality of the iterated accomplishment reading, it is striking that it occurs with the bare plural. Whatever semantic value we give the bare plural must make it admissible with this reading, as well as in activity sentences. In fact, the semantic value we have given the bare plural already does this.

\subsection{The bare plural in iterated accomplishment sentences}

Consider the difference in meaning between the following pairs.

John repeatedly counted some sheep.

John repeatedly counted sheep.

John counted some sheep three times.

John counted sheep three times.

(66) can only mean that the same set of sheep was repeatedly counted. (67), as previously noted, can have a meaning where the repeated counts were over different sets of sheep. A similar contrast holds for (68) and (69).

These sentences receive the following translations. 


$$
\begin{aligned}
& \exists \mathrm{X}: \forall \mathrm{t}\left[\mathrm { t } \in \mathrm { X } \rightarrow \left[\left[\exists \mathrm{Y}_{\text {sheepkff(t) }}: \forall \mathrm{i}\left(\mathrm { i } \in \mathrm { Y } \rightarrow \forall \mathrm { y } \left(\mathrm{y} \in\left(\text { sheep }_{\mathrm{ft}}^{\mathrm{k}}\right)_{\mathrm{i}}\right.\right.\right.\right.\right. \\
& \left.\left.\left.\left.\rightarrow \text { move-pointer '(j, y, t)))] \& [ assign' (j, FL, } \mid \text { sheep }_{\mathrm{f}(\mathrm{t})}^{\mathrm{k}} \mid, \mathrm{t}\right)\right]\right]\right] \\
& \exists \mathrm{X}: \forall \mathrm{t}\left[\mathrm { t } \in \mathrm { X } \rightarrow \left[\left[\exists \mathrm{Y}_{\text {sheep } \mathrm{f}(\mathrm{t})}: \forall \mathrm{i}\left(\mathrm { i } \in \mathrm { Y } \rightarrow \forall \mathrm { y } \left(\mathrm { y } \in \left(\text { sheep }_{\mathrm{ft}(\mathrm{t}))_{\mathrm{i}}}\right.\right.\right.\right.\right.\right. \\
& \left.\left.\leftrightarrow \text { move-pointer' }(\mathrm{j}, \mathrm{y}, \mathrm{t})))] \&\left[\operatorname{assign}^{\prime}\left(\mathrm{j}, \mathrm{FL},\left|\operatorname{sheep}_{\mathrm{f}(\mathrm{t})}\right|, \mathrm{t}\right)\right]\right]\right] \\
& \exists \mathrm{X}:|\mathrm{X}|=3 \& \forall \mathrm{t}\left[\mathrm { t } \in \mathrm { X } \rightarrow \left[\left[\exists \mathrm{Y}_{\text {sheepk } \mathrm{f}(\mathrm{t})}: \forall \mathrm{i}\left(\mathrm { i } \in \mathrm { Y } \rightarrow \forall \mathrm { y } \left(\mathrm{y} \in\left(\text { sheep }_{\mathrm{f}(\mathrm{t})}^{\mathrm{k}}\right)_{\mathrm{i}}\right.\right.\right.\right.\right. \\
& \left.\left.\rightarrow \text { move-pointer' }(\mathrm{j}, \mathrm{y}, \mathrm{t})))] \&\left[\operatorname{assign}^{\prime}\left(\mathrm{j}, \mathrm{FL}, \mid \text { sheep }_{\mathrm{f}(\mathrm{t})}^{\mathrm{k}} \mid, \mathrm{t}\right)\right]\right]\right] \\
& \exists \mathrm{X}:|\mathrm{X}|=3 \& \forall \mathrm{t}\left[\mathrm { t } \in \mathrm { X } \rightarrow \left[\left[\exists \mathrm{Y}_{\text {sheep } \mathrm{f}(\mathrm{t})}: \forall \mathrm{i}\left(\mathrm { i } \in \mathrm { Y } \rightarrow \forall \mathrm { y } \left(\mathrm{y} \in\left(\text { sheep }_{\mathrm{f}(\mathrm{t})}\right)_{\mathrm{i}}\right.\right.\right.\right.\right. \\
& \left.\left.\rightarrow \text { move-pointer' }(\mathrm{j}, \mathrm{y}, \mathrm{t})))] \&\left[\text { assign' }\left(\mathrm{j}, \mathrm{FL}, \mid \text { sheep }_{\mathrm{f}(\mathrm{t})} \mid, \mathrm{t}\right)\right]\right]\right]
\end{aligned}
$$

The superscript on the translation of the quantified NP in $\left(66^{\prime}\right)$ and $\left(68^{\prime}\right)$ forces the repetitions to be over the same set of sheep. This superscript is absent in (67') and $\left(69^{\prime}\right)$ and so the repetitions in these cases can be over different sets of sheep.

\subsection{Regimentation of atelic counting}

I return now to the question of what rules might constrain the activity of atelic counting. I have claimed that such rules depend on the purpose of the count. Here I discuss what I take to be one of the primary purposes of atelic counting, and what rules would be required for this purpose to be realized.

It is often of interest to know the number of individuals participating in repeated events. For example, one might want to know the number of cars that pass over a bridge in an hour. Since the concern is for the wear and tear on the bridge, it doesn't matter whether the same car crosses the bridge more than once. A car should be counted each time it crosses for the atelic count to provide information that is useful in the right way.

Clearly, there is something in common between atelic counting and the counting of events of the kind that Krifka (1990) discusses in relation to the eventrelated readings of certain sentences. It doesn't follow, though, that atelic counting just is the counting of events. I take it instead that in an atelic count particular events mark occasions for counting individuals -- the individuals participating in those events.

Consider the following case.

John counted people going over the falls in a raft.

Certainly, events are related to this counting. Every raft going over the falls marks an occasion for counting people on the raft. If John fails to count the people in any raft that goes over, or counts people more than once as a single raft goes over, there is something wrong with the way he is counting. 
I maintain that this is not a matter for the semantics. Rather, just as in the case of telic counting, there are certain rules that must be followed so that a particular aim can be reached. The semantics must be such that it describes an activity subject to the right sort of regimentation. If the purpose of the count is to determine the rate at which cars go over a particular bridge, for example, the rules must be such that an individual is counted once for each participation in an event of crossing, but no more than once per event.

Given the semantics assigned to atelic count in (50), the rules need only ensure that a set of indices is selected so that each corresponding subset contains all the individuals participating in a relevant event, and that for each such event, there is a such a subset.

\section{Conclusion}

Counting, I have claimed, involves the successive assignment of cardinal numbers to members of subsets of some set. Depending on how the subsets are chosen, the count yields different kinds of information. If the subsets form a partition of the set, the count yields the cardinality of the set. If the subsets are chosen so that each contains individuals participating in a repeating event, the count can yield a rate -- the number of individuals over a given interval that participate in an event of the right type.

The English transitive verb count takes different kinds of direct objects. If the direct object is an individual-denoting expression, or one that denotes a generalized quantifier, count means to include in a count. If the direct object is a quantified NP such as some sheep, count is readily interpreted as an accomplishment verb. If the direct object is a bare plural, count is readily interpreted as an activity verb, or one associated with iterated accomplishments.

The reason these interpretations are natural is found in the type of object denoted by the NPs. some sheep in these contexts denotes a function to a fixed set. Such a set will be a natural object over which to assign a cardinality. The bare plural sheep denotes a function to any set. It is natural to read a counting sentence with a bare plural object atelicly, since a bare plural allows the extent of the set to depend on the extent of the counting activity.

In addition, since a bare plural can denote different sets at different intervals, sheep is an appropriate direct object in an iterated accomplishment sentence expressing the notion that at different times, different sets of sheep are counted and assigned cardinalities.

\section{Endnotes}

* I would like to thank Ron Artstein, Christine Brisson, Bruce Hall, Markus Hiller, Cecile Meier, Roger Schwarzschild, and Mandy Simons for comments and suggestions. Special thanks go to Veneeta Dayal, out of whose seminar on kinds and bare plurals this paper arose and who has helped me at every step. 
1. In this paper, I ignore tense in all but the most straightforward cases.

2. Moltmann (1997) discusses similar cases of miscounting, including a case where the counter mishandles numbers. Moltmann's conclusion -- that count has a sense which is intensional -- is very different than the conclusion I reach in this paper.

3The idea for this formulation of counting came about while thinking about Brisson's (1998) treatment of exceptions.

4. Veneeta Dayal suggested that I look at such examples.

5. (i) may also be odd, but can be improved by context, as in (ii).

(i) ?John cured some healthy rabbits.

(ii) John cured some healthy rabbits we saw in the backyard.

(32), on the other hand, cannot be improved by context.

(iii) \#John cured healthy rabbits we saw in the backyard.

\section{References}

Brisson, Christine (1998): Distributivity, Maximality and Floating Quantifiers. Rutgers Dissertation..

Dowty, David R. (1979): Word Meaning and Montague Grammar. Dordrecht: D. Reidel Publishing Company.

Kamp, Hans and Uwe Reyle (1993): From Discourse to Logic. Dordrecht: Kluwer Academic Publishers.

Krifka, Manfred (1990): Four Thousand Ships Passed Through the Lock: ObjectInduced Measure Functions on Events. Linguistics and Philosophy. 13: 487-520.

Moltmann, Friederike (1997): Intensional Verbs and Quantifiers. NaturalLanguage Semantics. 5: 1-52.

Musan, Renate (1995): On the Temporal Interpretation of Noun Phrases. Cambridge: MIT Dissertation.

Smith, Carlota S. (1997): The Parameter of Aspect. Dordrecht: Kluwer Academic Publishers.

Vendler, Zeno (1967): Linguistics in Philosophy. Ithaca: Cornell University Press. 